\title{
Development of hydraulic models for a complex and large scale water distribution system in regional Australia
}

\author{
$\underline{\text { H. Mala-Jetmarova }}^{\text {a,b }}$, S. Schwarz ${ }^{\text {a }}$, A. Barton ${ }^{\text {a,b }}$, S. Le Roux ${ }^{\text {a }}$, P. Smalley a and S. Gerke ${ }^{\text {c }}$ \\ ${ }^{a}$ Grampians Wimmera Mallee Water (GWMWater), 11 McLachlan Street, Horsham, Victoria 3400, Australia \\ ${ }^{\mathrm{b}}$ School of Science, Information Technology \& Engineering, University of Ballarat, Mt Helen Campus, \\ University Drive, Ballarat, Victoria 3353, Australia \\ ${ }^{\mathrm{c}}$ Innovyze, Suite 38, 75 Wharf Street, Tweed Heads, New South Wales 2485, Australia \\ Email: helena.jetmarova@gwmwater.org.au
}

\begin{abstract}
Hydraulic simulation models have become a valuable tool to manage water distribution networks commencing from their initial design through their operation, assessment of the level of service to customers, system performance improvement, analysis of planning alternatives, to system optimisation. The development of hydraulic models can be a time consuming task with complex and large scale water distribution networks being particularly challenging.
\end{abstract}

The Wimmera Mallee Pipeline (WMP) in Western Victoria, Australia is a recently constructed and unique regional scale water distribution system which consists of over $8,800 \mathrm{~km}$ of pressurised pipelines spreading across an area of approximately $20,000 \mathrm{~km}^{2}$. Currently, the WMP provides water to 34 townships, rural farms and other water users across the Wimmera Mallee region with an annual design capacity of $31.6 \mathrm{mil} . \mathrm{m}^{3}$. The WMP sources its water from multiple reservoirs in the Grampians mountain ranges in the south and the River Murray in the north.

Grampians Wimmera Mallee Water (GWMWater) is the local water organisation responsible for managing the WMP. GWMWater is currently initiating the development of a water market to generate and support growth, and to ensure that water is available for the highest value social, economic or environmental use. The hydraulic models discussed in this paper will assure that informed decisions are made by GWMWater regarding the capacity to deliver water through the pipeline system, and therefore the extent of trade by customers.

The philosophy for development of the WMP hydraulic models was to replicate the real system as credibly as possible into the level of required accuracy for decision making, yet enable simple model operation, maintenance and update. The network is modelled to the individual customer level in order to accommodate small diameter pipes. Modelling at this level simplifies the future model maintenance and updates, and also ensures the compatibility with other GWMWater's systems such as Geographic Information System (GIS) and the customer database.

A major part of the model development consisted of data preparation. This was undertaken by using "as constructed" GIS asset data captured during the WMP construction and entered into a GIS database (ArcGIS by ESRI). Due to the scale of the system and associated amounts of data, it was essential to develop sophisticated data transformation and validation procedures to simplify the model build which thereby minimised manual data entry and potential sources of errors.

This paper focuses on the methodologies and techniques used in data preparation for hydraulic models and development of hydraulic models. An example is also provided of how the models will be used as a decision support tool in water supply and allocation planning.

Keywords: Hydraulic model, Wimmera Mallee Pipeline (WMP), data preparation, model development, water allocations 


\section{INTRODUCTION}

The Wimmera Mallee region is a semi-arid rural area in Western Victoria, Australia, where agriculture represents the significant proportion of the region's economic base (Schwarz, 2007). Historically, water supply was provided through a vast earthen open channel system titled the "Wimmera-Mallee Domestic and Stock Supply System" (Anon, 1984) which consisted of 19,500 km of channels spreading across an area of $28,500 \mathrm{~km}^{2}$.

The channel system was sourced from reservoirs in the Grampians mountain ranges, and water was delivered to earthen town storages and farm dams on a seasonal basis. Annual volumes in the order of $120 \mathrm{mil} . \mathrm{m}^{3}$ were required to satisfy both water consumption and transmission losses in the channel system through seepage and evaporation. These losses could account for up to $85 \%$ of water entering the system (MalaJetmarova et al., 2010).

During the period from 1997 to 2009, the Wimmera Mallee region experienced severe drought conditions which placed considerable stress on the entire region, including its economic, social and environmental base (WIDCORP, 2006). As Victorian water supply systems became increasingly under stress with the rest of Australia, according to Porter et al. (2005), "the need for supplementing these supplies was at the forefront of water organisation planning and community expectations."

Subsequently, the inefficient earthen open channel system was replaced with a pressurised pipeline system the WMP which was constructed between 2006 and 2010. Based on historical inflows into the reservoirs and projected demands, it is estimated that the WMP will save, on average, $103 \mathrm{mil} . \mathrm{m}^{3}$ per year with the bulk of these water savings being returned to the environment (Barton et al., 2009).

The WMP is a unique regional large scale water distribution system which forms part of the Victorian water grid (Office of Water, 2011). The location of this pipeline is illustrated in Figure 1. The WMP consists of over $8,800 \mathrm{~km}$ of pressurised pipelines supplying an area of approximately $20,000 \mathrm{~km}^{2}$. It currently provides water to 34 townships, rural farms and other water users with an annual design capacity of 31.6 mil. $\mathrm{m}^{3}$. The WMP is sourced from multiple reservoirs in the Grampians mountain ranges in the south such as Lake Bellfield, Taylors Lake and Lake Wartook, and the River Murray in the north via Swan Hill pump station.

The WMP is constructed with seven discrete supply systems namely Supply System 1 (SS1) through to Supply System 7 (SS7) (Figure 2). In consideration of the total $8,800 \mathrm{~km}$ of pipelines, $1,200 \mathrm{~km}$ account for trunk mains and $7,600 \mathrm{~km}$ for distribution mains. The system also includes 32 pump stations incorporating 45 pump sets, 22 open earthen balancing storages and 29 covered steel tanks. Additional information about the WMP system can be found in Mala-Jetmarova et al. (2010) and Mala-Jetmarova et al. (2012).

Local water organisation, GWMWater, which is responsible for managing the WMP, is actively initiating the development of a

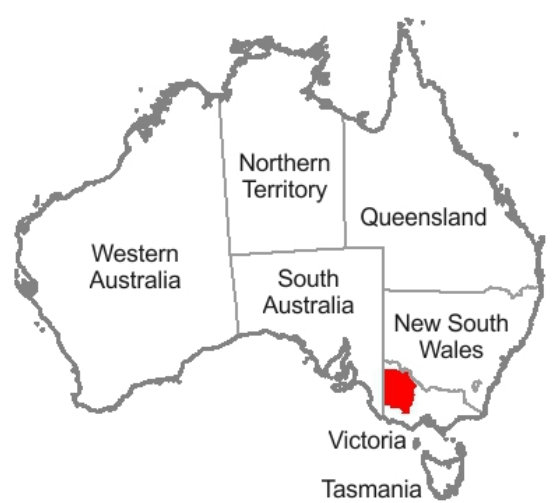

Figure 1. Location of the Wimmera Mallee Pipeline in Western Victoria, Australia. water market to enable customers to purchase and trade available water. The primary reason for establishing a viable water market and trading regime within the pipeline system is to generate and support growth (Schwarz, 2011), and to ensure that water caters for the highest value social, economic or environmental use.

Hydraulic models have proven to be a valuable tool to support decision making. Typically, a hydraulic model can be employed to ensure the adequate quantity and quality service of the potable water resource to the community, to evaluate the planning and design alternatives, to assess the system performance and to verify an operating strategy for better management of a water infrastructure system, as well as to be able to perform vulnerability studies to assess risks that may be presented and affect the water supply (Wu and Clark, 2009).

The hydraulic models discussed in this paper are intended to provide GWMWater with a decision support tool in relation to the capacity of the WMP. As such, the availability of source water at Grampians reservoirs and Murray River, respectively, is not explicitly modelled as constraint. The hydraulic models will support informed decisions regarding the capacity to deliver water through the pipeline system, and therefore the extent of potential trade by customers. 
Mala-Jetmarova et al., Development of Hydraulic Models for a Complex and Large Scale Water...

\section{INITIAL CONSIDERATIONS}

Prior to development of the hydraulic models for the WMP, numerous considerations were discussed to ensure the new models would meet organisational needs. These included:

- Models to "be fit" for future decisions associated with water allocations, system operation and planning.

- Determining if the representation of small diameter pipes is important.

- Ensuring simple model operation, maintenance and update.

- Selection of a modelling package which is compatible with GWMWater's systems and ability to represent variable speed drive pumps, a feature of the WMP.

- Integration of the models with other GWMWater systems including GIS and customer databases.

- Accuracy and availability of sufficient data for the model build.

To achieve the required accuracy of model predictions and to ensure that the model will meet future needs, it was important to balance model simplicity with model detail (Boulos et al., 2006). As such, the modelling philosophy of the WMP was to replicate the real system to be as credible as possible and into the level of required accuracy for decision making. Additionally, it was considered extremely important to enable future simple model operation, maintenance and update.

The models were simplified mainly around pump stations and storage facilities. The pipe network is modelled to the individual customer level in order to accurately represent small diameter pipes (63 $\mathrm{mm}$ and smaller) which form 52 per cent of the entire network. Modelling at this level simplifies the model maintenance and integration with other GWMWater systems such as GIS and the customer database. The models have also been designed to ensure that potential future updates can be made efficiently through compatibility

with GWMWater's systems.

Careful attention was paid to the selection of the modelling software. This included considerations for not only the suitability for

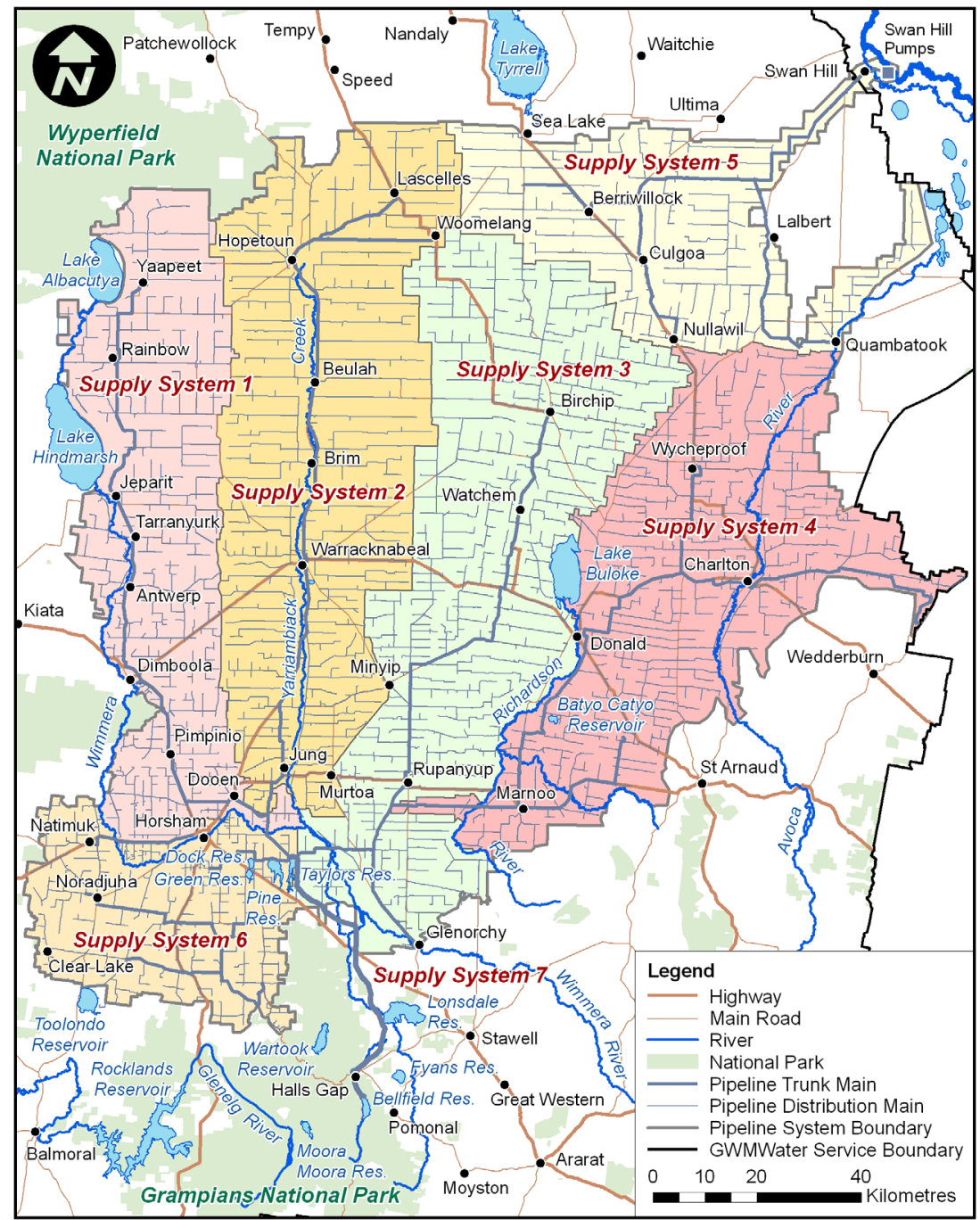

Figure 2. Location Map of the Wimmera Mallee Pipeline (Mala-Jetmarova et al., 2012).

the pipe network in question, but also conversion of the existing GWMWater's hydraulic models into the new modelling package. The modelling software selected to perform the analysis was InfoWater by Innovyze (http://www.innovyze.com/products/infowater). InfoWater is a GIS integrated water distribution modelling and management software application which is built atop ArcGIS using the Microsoft .NET and ESRI Arc Objects component technologies. InfoWater integrates advanced water network modelling functionality using an optimised version of the EPANet 2.0 hydraulic simulation engine. InfoWater was chosen as the preferred 
modelling platform due to its ability to model complex operational scenarios, accurately represent variable speed drive pumps and ability to integrate well with GWMWater's GIS system.

\section{DATA PREPARATION FOR HYDRAULIC MODELS}

A significant component of the model development consisted of data preparation to ensure the simplicity of model build which thereby minimised manual data entry and potential sources of errors. Data for the model was obtained from various sources as presented in Figure 3, and is described in the following sections.

\subsection{Network Data: GIS}

Network data for model development is represented by "as constructed" GIS asset data which was captured during the WMP construction and subsequently stored into a GIS database (ArcGIS by ESRI, http://www.esri.com/products/index.html\#desktop_gis_panel). This data was then transformed using spatial analysis techniques to ensure that it was suitable for the model build and required analysis. Due to the scale of the WMP system and associated amounts of data, it was essential to develop sophisticated data transformation and validation procedures. These included three major elements:

- Development of geometric network including checks of attribute fields.

- Generation of service lines.

- Topology tests.

A geometric network was developed to verify the network tracing ability and connectivity. All pipes in the network were assigned a unique identification number. The compulsory fields of each network attribute (pipes, pumps, valves, etc.) were then subjected to checks to validate that all fields were populated correctly. The compulsory attribute fields included, for example, pipe internal diameter, pipe class, pipe roughness coefficient, elevation of valves and pumps.

Service lines were generated to connect individual water meters (demand nodes) to the network. This process consisted of auto generating a service line to the closest main but within a number of rules. The service line would not be allowed to "snap" to an air valve/scour valve line or pipe work inside a facility.

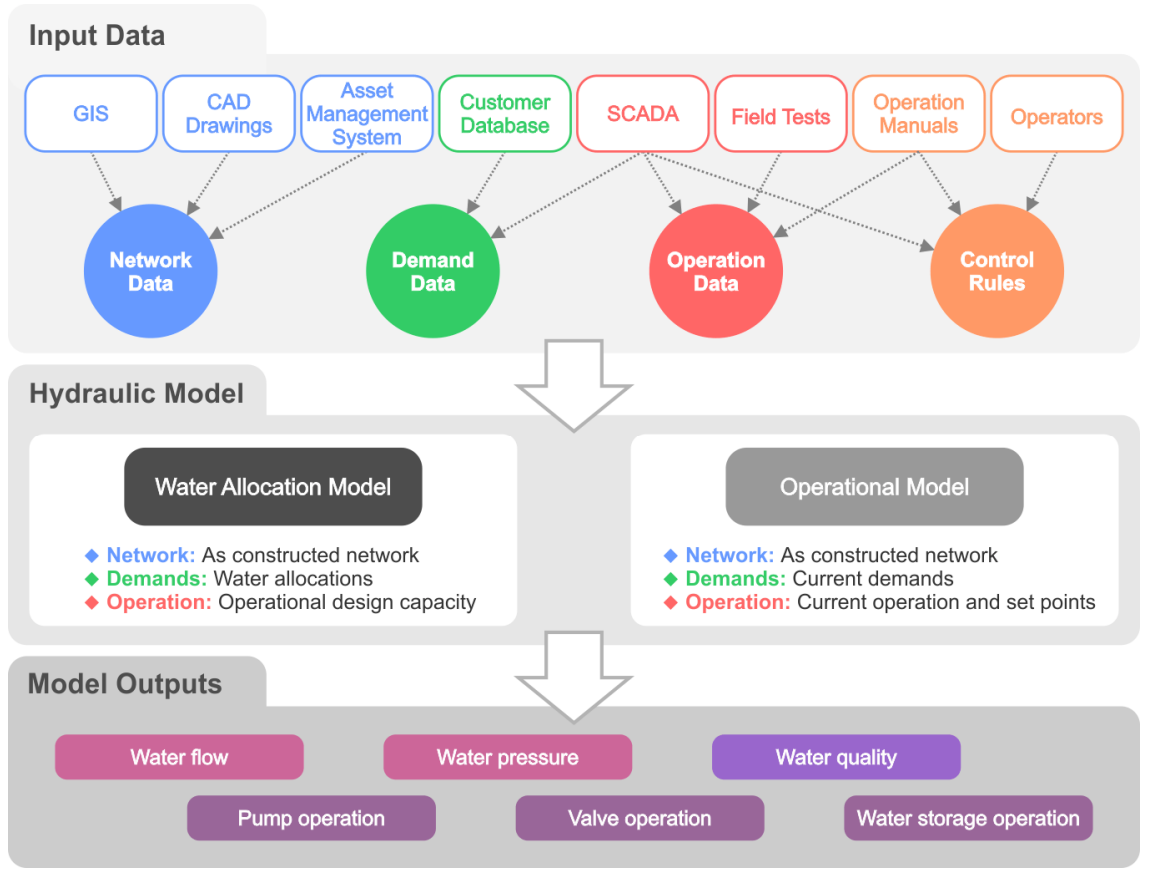

A number of topology tests were undertaken to

Figure 3. Flowchart Describing Modelling Process.

ensure that data was cleansed from basic topology errors. The topology tests and checks included nodes not "snapped" to pipe, duplicate nodes, duplicate pipes, pipe intersections, short pipes and checks for flow direction.

As a result of the substantial network data validation prior to its entry into the models, the initial phase of model development, which is usually a time consuming task due to the extent of manual corrections of network data errors, was significantly accelerated.

\subsection{Demand Data}

Demand data were described as two sets representing water allocations and current (metered) demands. Because the network is modelled to the individual customer level using water meters as demand nodes, it was 
necessary to link both demand sets directly to water meters. In the customer database, metered demands are already linked to water meters, whereas water allocations are linked to properties which can consist of several land parcels. Each property can have multiple water meters.

To link water meters to properties and land parcels, meters were captured using Global Positioning System (GPS) at the meter installation stage. Meter serial numbers were then verified and linked to land parcels and properties through GIS for subsequent importation into the customer database. Water meter attributes consist of meter serial number, installation date, meter size, identification number of property, land parcel and connection.

Water allocations were assigned to individual water meters by dividing total property allocation by a number of meters on the particular property. However, in practice, more allocated water may be taken through an individual meter than others for a given property.

\subsection{Operation Data and Control Rules}

Operational data such as pump performance curves, set points and control rules were sourced as indicated in Figure 3 from field tests, the SCADA (Supervisory Control and Data Acquisition) system, operations manuals or directly from system operators.

\section{DEVELOPMENT OF HYDRAULIC MODELS}

\subsection{Model Development}

Development of the hydraulic models involved several steps consisting of:

- Importing network data.

- Engineering and network validation.

- Identification and amendment of missing network data.

- Scenario development.

- Allocation of system demands and demand patterns.

- Allotment of operational data.

- Model simulation and output analysis.

The WMP network (Table 1) GIS data such as pipes including service lines, storage facilities, pumps, valves, hydrants and water meters were imported into a model using InfoWater GIS Gateway Tool. Network data is represented in the models by about
Table 1. Wimmera Mallee Pipeline Attributes (Mala-Jetmarova et al., 2010).

\begin{tabular}{|c|c|c|}
\hline Storage Facilities & Number & Volume $\left(\mathrm{m}^{3}\right)$ \\
\hline Earthen lined storage & 22 & 37,000 \\
\hline Covered steel tank & 29 & 522,000 \\
\hline Total & 51 & 559,000 \\
\hline \multicolumn{2}{|l|}{ Pump Sets } & Number \\
\hline \multirow{3}{*}{\multicolumn{2}{|c|}{$\begin{array}{l}\text { Trunk pump sets } \\
\text { Distribution pump sets } \\
\text { New town pump sets }\end{array}$}} & 21 \\
\hline & & 16 \\
\hline & & 8 \\
\hline \multicolumn{2}{|l|}{ Total } & 45 \\
\hline \multicolumn{2}{|c|}{ Other Pipeline Infrastructure } & Number \\
\hline \multirow{4}{*}{\multicolumn{2}{|c|}{$\begin{array}{l}\text { Air valve } \\
\text { Scour valve } \\
\text { Hydrant } \\
\text { Tapping connection } \\
\end{array}$}} & 16,886 \\
\hline & & 1,225 \\
\hline & & 355 \\
\hline & & 9,000 \\
\hline
\end{tabular}

146,900 network attributes (nodes, pipes, pumps, tanks, reservoirs and valves) (Figure 4). Network review and validation tools were utilised to identify gaps in the GIS data. These were amended in the model and reported back to the GIS system. Additional network data which were not a part of the initial data import such as storage diameters, storage depth-volume characteristics, pump diameters and others, were manually entered into the model.

The next step in model development was to implement an appropriate model structure, which was to ensure the model would meet required future needs. This was achieved by development of facility sets, valve sets, demand sets and control sets which were then combined into scenarios or sub-models.

Demand data was obtained by joining water meter data from the GIS database and demand data from the customer database. Demands were then spatially allocated using InfoWater Demand Allocator Tool. Demands which are not contained in the customer database such as town and environmental demands were identified and imported separately into the model.

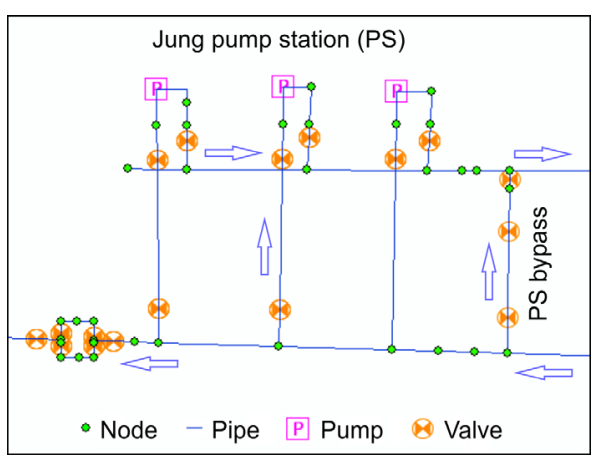

Figure 4. Model Attributes. 
Operational data and control rules were implemented to reflect two modelling scenarios being (1) a water allocation model and (2) an operational model. The water allocation model reflects the full (or design) capacity of the system, whereas the operation model simulates current (actual) system operation. In the operational model, variable speed drive pumps are modelled accordingly with current pressure set points using InfoWater Control Rules.

To create model runs for the expected range of flows, several simulation errors required to be resolved. These were mainly errors caused by either disconnection of a part of the network usually due to an incorrect pump setting, or errors resulting from a hydraulically unbalanced network.

\subsection{Model Structure}

Because there was a requirement that the hydraulic models were to support decisions not only on water allocation planning, but also issues related to system operation, this needed to be addressed by a suitable model structure which also reflects the network layout.

There are two discrete models; the "Murray" model consisting of SS5 which sources its water from the River Murray via Swan Hill pump station, and "Grampians" model consisting of SS1 to SS4, SS6 and SS7 which sources water from reservoirs within the Grampians mountain ranges such as Lake Bellfield, Taylors Lake and Lake Wartook. Each of these models comprises of the two water allocation and operational sub-models (Figure 3). These were developed using InfoWater Scenario Manager Tool through a combination of facility sets, valve sets, control sets and demand sets. This model structure was implemented in order to enable effective and timely model use.

\section{FUTURE MODEL DEVELOPMENTS: CALIBRATION, VALIDATION AND APPLICATION}

To ensure that hydraulic models give correct predictions, they must reflect the real conditions in the field. This is achieved by calibrating and validating the models. A model calibration involves adjustments of model parameters to ensure that the model results (flows and pressures) agree with the field values (Walski, 2001) in consideration of the required level of accuracy.

There are two types of data available for model calibration and validation, the first type is SCADA data and the second type is data gained from temporary field monitoring installations. SCADA data represents flow, pressure and water levels and is available at network facilities such as pump stations, storages and control valves. Data from temporary field monitoring, conducted from January to July 2011, was collected from portable data loggers to provide complementary pressure values at the extremities of the network.

In future, the hydraulic models will be extended to include water quality models using InfoWater MultiSpecies Extension (MSX) (http://www.innovyze.com/products/infowater/index.aspx\#msx) which enables modelling of multi-source and multi-quality WDSs.

Developed hydraulic and water quality models will be used as a decision support tool for a wide range of system operational and planning challenges. Operational scenarios include assessment of effective use of the system spare capacity (ie. growth water supply during off peak season), resolution of sporadic hydraulic issues (ie. pressure) and support in emergency supply incidents (ie. upstream supply interruption).

The immediate anticipated planning challenges include allocations of growth water for use in and out off peak periods, trading of customers' water allocations and transfer of entitlements, assessment on intensive users and supply by agreement (SBA) applications, analyses of requests for pipeline extensions for new and outside district customers, and eventually the use of the pipeline network for access by third parties. With an increase in water availability, the models will be also required to assist in decisions related to seasonal supply for community facilities and environmental requirements (ie. flow rate, timing and source of supply). In the future, the models will be used to analyse planning for system outages for maintenance and repair, staging of implementation of deferred works as demand increases, and possibly also cross-linking supply systems and looping existing networks. To assure more effective use of the WMP system, the models will additionally assist in planning for improved system operation such as optimisation of pumping, improved water quality and maximization of water availability.

\section{DISCUSSION AND SUMMARY}

Operational hydraulic models for the WMP in Western Victoria are progressively being developed, which will have an important role in supporting decisions made in relation to water delivery from this significant regional water distribution system. 
Data preparation, in particular preparation of GIS network data, has played a crucial role in model development and minimised any subsequent manual data entry into the model which then enabled the timely progress of the project. Selection of the modelling software (InfoWater by Innovyze) was of vital importance and assured compatibility with GWMWater's GIS system and the ability to represent variable speed drive pumps, a feature of the WMP.

Future model developments will include calibration and validation using SCADA data which is supplemented by data gained from temporary field monitoring. Additionally, water quality models will be implemented in the future which will add an additional dimension to decision makers for the optimal selection of source water where choices may exist.

The developed hydraulic and water quality models will be used for a wide range of operational and planning challenges. These include the optimisation of pipeline operations for pump scheduling, selection of source water for quality reasons, general operational improvements and efficiencies, and predictions for asset management, system refinement or system reconfigurations. The models will also be used to support an emerging water market for the region particularly for the sale and allocation of new water for regional development, and to facilitate trade between GWMWater customers. In supporting the water market, the models will be used for the purpose of determining spare capacity and constraints of the pipeline system. They will be central to the decision making process of allocating new water for growth or in permitting a trade.

\section{ACKNOWLEDGMENTS}

The authors thank GWMWater for supporting this paper.

\section{REFERENCES}

Anon (1984). It's Big by Any Standard - The Wimmera-Mallee Domestic and Stock Supply System. AQUA, 23(3), 27-28.

Barton, A. F., Briggs, S., McRae-Williams, P., and Prior, D. (2009). Coping with Severe Drought: Stories from the Front Line. In: 32nd Hydrology and Water Resources Symposium, Newcastle, Australia, 30 November - 3 December 2008. Published on CD.

Boulos, P. F., Lansey, K. E., and Karney, B. W. (2006). Comprehensive Water Distribution Systems Analysis Handbook for Engineers and Planners, second ed., MWH Soft, Pasadena, California, USA.

Mala-Jetmarova, H., Barton, A., Bagirov, A., McRae-Williams, P., Caris, R., and Jackson, P. (2010). Adaptation to Water Shortage through the Implementation of a Unique Pipeline System in Victoria, Australia. In: HydroPredict' 2010, 2nd International Interdisciplinary Conference on Predictions for Hydrology, Ecology, and Water Resources Management, Prague, Czech Republic, 20 - 23 September 2010. Published on CD.

Mala-Jetmarova, H., Barton, A., and Briggs, S. (2012). Securing Water Supply in Western Victoria through the Implementation of Regional Pipeline Systems. In: Managing a Scarce Water Resource through Reform, Conservation and Adaptation, M. Graymore, P. McRae-Williams, A. Barton, and L. Lehmann, eds., Water in Drylands Collaborative Research Program (WIDCORP), Horsham, Victoria, Australia. Accepted August 2011.

Office of Water (2011). Expansion of the Water Grid: Wimmera Mallee Pipeline. Available on http://www.water.vic.gov.au/programs/water-grid/wimmera-mallee (accessed on 28 April 2011).

Porter, N. B., Leviston, Z., Nancarrow, B. E., Po, M., and Syme, G. J. (2005). Interpreting Householder Preferences to Evaluate Water Supply Systems: An Attitudinal Model. CSIRO: Water for a Healthy Country National Research Flagship, Land and Water: Perth.

Schwarz, I. (2007). Adapting to and Maximising Opportunities from Water Pipeline Projects in Dryland Regions: Literature Review. Water in Drylands Collaborative Research Program (WIDCORP), Horsham, Victoria, Australia.

Schwarz, S. A. (2011). Changing the Channel. Civil Engineering Surveyor, April 2011, 31-33. Available on http://mag.digitalpc.co.uk/fvx/ces/1104/ (accessed on 28 April 2011).

Walski, T. M. (2001). Understanding the Adjustments for Water Distribution System Model Calibration. Journal of Indian Water Works Association, April-June 2001, 151-157.

WIDCORP (2006). Desk-based Review 20 November 2006. Prepared for the Wimmera - Southern Mallee Drought Report 2007. Water in Drylands Collaborative Research Program (WIDCORP), Horsham, Victoria, Australia.

Wu, Z. Y., and Clark, C. (2009). Evolving Effective Hydraulic Model for Municipal Water Systems. Water Resources Management, 2009(23), 117-136. 